\title{
Diagnosis and Management of Female Pattern Hair Loss
}

\author{
Sarah Diba ${ }^{1 \#}$, Maria Mayfinna Gozali ${ }^{1}$, Yuli Kurniawati ${ }^{1}$ \\ ${ }^{1}$ Dermatology and Venereology Department, Faculty of Medicine Universitas Sriwijaya, Palembang, Indonesia \\ \#Corresponding Author E-mail: sarah_diba_dr@yahoo.com
}

Received : October $23^{\text {rd }} 2019$

Accepted : December $2^{\text {th }} 2019$

\begin{abstract}
Female pattern hair loss (FPHL) is the most common hair loss in post-puberty female. Prevalence of this nonscarring alopecia increases with age. The etiology of FPHL is still unclear, but hormonal and genetic factors are associated with pathogenesis of FPHL. Hormonal factor in FPHL is not as strong as in male pattern hair loss (MPHL). Clinical manifestations of FPHL are characterized by nonscarring baldness with shortening anagen phases and miniaturization of hair follicles, predominantly occur at the vertex, middle, and frontal regions. Hair shedding occurs progressively. The diagnosis of FPHL is established based on clinically. Classification of FPHL is according to Ludwig's criteria. Current FDA-approved FPHL therapy is topical minoxidil 2\%, hair transplantation, and low level laser therapy (LLLT). Anti-androgen therapy still needs to be investigated further. The prognosis of FPHL is poor because the progressiveness continues with age. Long term treatment required for FPHL because it is a chronic residif disease. The treatment only prevents the progression of hair loss and does not cure.
\end{abstract}

Key words: female pattern hair loss, female androgenetic alopecia, minoxidil, low level laser therapy, antiandrogen

\section{Introduction}

Female pattern hair loss (FPHL) is a broad term for the decrease of hair density on cental scalp that affects post-puberty female. The other term that refer to FPFL are female androgenetic alopecia (AGA) and androgenic alopecia. Both term imply a specific androgenrelated and genetic predispotition. ${ }^{1}$ The role of androgen in FPHL is less clear than in male pattern hair loss (MPHL). ${ }^{2}$ It has not been prove that FPHL clearly has androgen-related process. $^{1,2}$

Clinically, FPHL is noncicatricial pattern hair loss characterized by hair progressive thinning affecting mainly frontovertical region of the scalp. ${ }^{2}$ The epidemiology data of FPHL varies among population groups and ordinarily increase with age. Mostly, FPHL affects more than $50 \%$ female over the age of 50 years. Based on the onset of FPHL were classified in 
early-onset (post-puberty to third decades) and late-onset (above 40 years old). ${ }^{1}$ About $40 \%$ of Caucasian female experienced FPHL by 70 years. $^{2}$

The main goal of management of FPHL is to arrest hair loss progression and stimulate hair regrowth. ${ }^{3}$ In early phase, topical minoxidil is recommended by Food and Drug Administration (FDA), but unresponsive case to minoxidil, finasteride, hair transplantation, low level laser therapy (LLLT), or/and hair piece can be an alternative. ${ }^{2,4}$ Several treatment modalities still need further investigation, such as microneedling and platelet rich plasma $(\mathrm{PRP}) .^{5}$

In this article, we review about the diagnosis and management of FPHL that may cause psychological distress and impaired social functioning for affected woman. Early diagnosis and adequate initiation of treatment are desirable. Avoiding the progression of hair loss would be more effective than stimulating regrowth. The treatment only prevents the progression of hair loss and does not cure.

\section{Etiopathogenesis}

The pathogenesis of FPHL is still remain unclear, FPHL is associated with androgen and genetic factors. ${ }^{1}$ However, not all cases of FPHL have elevated androgen hormone levels. In the hair follicle there are 5- $\alpha$-reductase and aromatase enzymes that metabolize androgen hormones. $^{1,6} 5$ - $\alpha$-reductase enzymes consist of 2 types namely I and II. (Figure 1) This enzyme functions to change testosterone to dihydrotestosterone (DHT) which has a 5 times greater affinity for hair androgen receptors responsible for gene transcription in target cells so that it can cause hair miniaturization. ${ }^{3}$ In addition, DHT interferes with the hair follicle cycle through the wingless type (Wnt). The Wnt pathway causes the dermal papilla to remain in the anagen phase. Some individuals with FPHL have low levels of sex hormone binding globuline (SHBG) thereby increasing the amount of free testosterone in hair follicles. ${ }^{6,7}$

Genetic factor on FPHL is still unclear. ${ }^{4}$ In women with FPHL, the incidence of hair loss in parents or siblings over 30 years old in men is $54 \%$ and in women is $21 \% .^{1}$ About 40 $54 \%$ family member of FPHL patient were affected, especially in early-onset cases. ${ }^{8}$ The strong evidence that shows gene involvement in man is the presence of androgen receptor gene (RA) polymorphisms located on the long arm of the $\mathrm{X}$ chromosome (Xq11-12). Polymorphisms in the first exon RA gene, known as Stul, are associated with baldness. The 
ISSN 25980580

RA gene contains the amino acid CAG on the first exon, variations in length and the amount of amino acid CAG on chromosomes are associated with the risk of baldness. The shorter the CAG repetition $(<15)$ in gene transcription, the stronger the relationship with baldness, it is about $97.3 \%$. However, there is less evidence of the role of AR gene in FPHL than in male pattern alopecia. ${ }^{6,9}$

\section{Clinical Manifestation and Classification}

The characteristics of FPHL are noncicatricial hair loss, with an increase in scalp hair miniaturization, thinning of the hair in the frontal, central, and parietal areas while the frontal hairline remains. This is due to the shortening of the anagen phase and the reduction in size of hair matrix. ${ }^{2,9}$ The pattern of baldness in FPHL is divided into 3 patterns: diffuse thinning of crown with preservation of the frontal hairline [3-point Ludwig scale and 5-point Sinclair scale], thinning and widening of the central part of the scalp with breach of frontal hairline that covers the superior part of the head but thinning hair widens on the frontal area to form a triangular area like a christmas tree (Olsen scale), and thinning associated with bitemporal recession, similar as baldness in male (Norwood-Hamilton scale). ${ }^{9,10,11}$ (Figure 1)

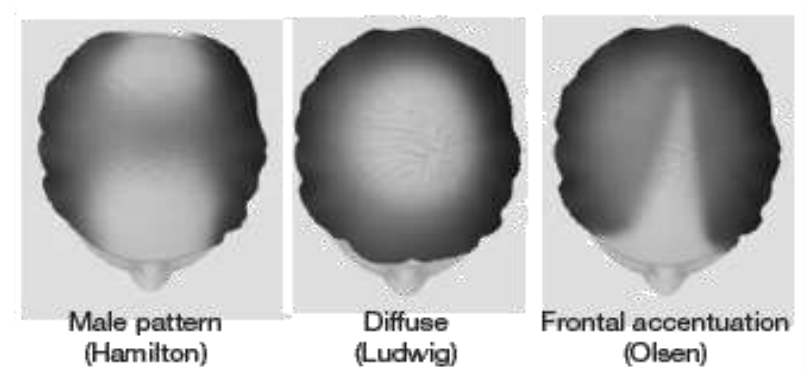

Figure 1. FPHL pattern of baldness ${ }^{2}$

The most widely used FPHL classification is the Ludwig (1977) classification. This classification is characterized by diffuse baldness on the area of the corona and the permanent frontal hairline. Ludwig divides FPHL into 3 point scale: grade I, thinning hair in the corona area, limited to $1-3 \mathrm{~cm}$ behind the frontal line; grade II, thinning hair is increasingly apparent in the area of grade I; grade III, total baldness in the area of grade I and II. (Figure 2) 


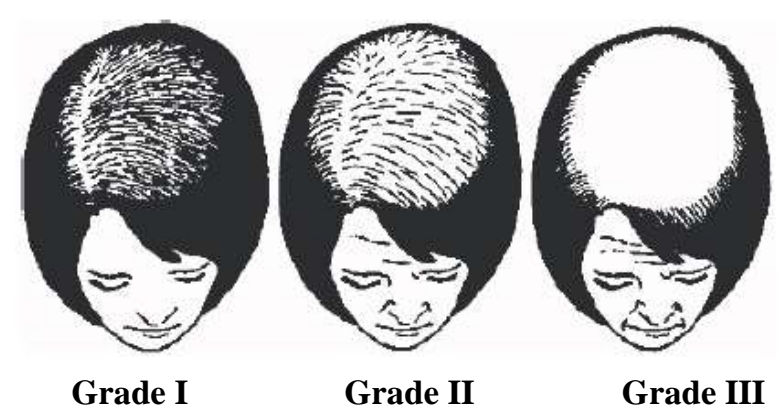

Figure 2. 3-point Ludwig scale for grading of FPHL ${ }^{1}$

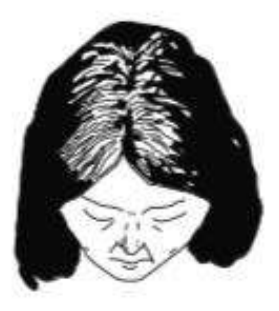

Grade I

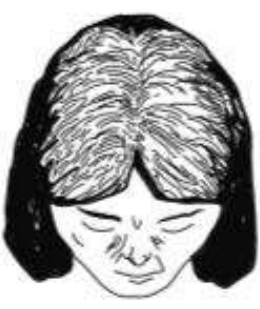

Grade II

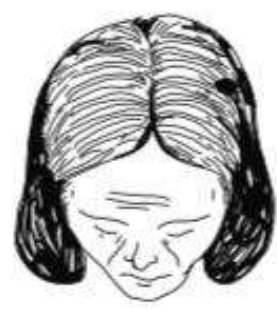

Grade III

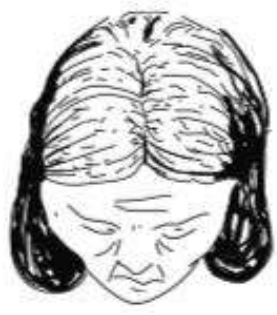

Grade IV

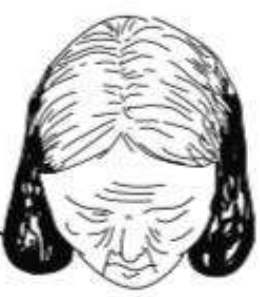

Grade V

Figure 3. 5-point Sinclair scale for grading of $\mathrm{FPHL}^{6}$

\section{Examination and Diagnostic Tools}

Several examinations in FPHL such as clinical examination of skin and hair, as well as the nail, hair pull test, trichogram, trichoscopy, histopathology, and laboratory examination can be done to establish the diagnosis. ${ }^{2,9,12}$ Some diagnostic tools need to be done if the clinical diagnosis of FPHL is still uncertain or there are doubts about other diseases. ${ }^{2}$

Hair pull test (Sabouraud's sign) is a noninvasive diagnostic technique that shows an increase in telogen hair release. To do a hair pull test, the patient should not clean hair with shampoo 24 hours before. ${ }^{10}$ The examination is done by grasping 50-60 hairs with thumb, index finger, middle finger from the base of the hair, then hair pulled slowly with the direction of the fingers following the hair shaft. The examination is carried out in the left and right parietal regions, frontal and occipital. Removal of six hairs indicates a positive pull test and active shedding. ${ }^{2}$ In FPHL, positive results if limited to the area affected during the active phase. If positive results occur in several regions of the head, a diagnosis of telogen effluvium is considered. ${ }^{10}$ 
Trichogram is a semi-invasive examination technique by pulling hair using a needle holder and analyzing 50-100 hairs from the scalp under the light of a microscope. This check calculates the anagen: telogen hair ratio. In the early stages of FPHL, the trichogram shows a hair shaft that is not homogeneous. ${ }^{9,10}$

Scalp tricoscopy or dermoscopy is a non-invasive diagnostic tool that is useful for diagnosing early-stage FPHL. Characteristics of FPHL on trichoscopy are differences in hair diameter or thickness $>20 \%$ with an increase in hair miniaturization, especially the frontoparietal region. ${ }^{10}$ At the initial stage of FPHL examination, peripillary markings, light brown areas, slightly atropic around follicles appear. This sign shows the relationship of inflammatory infiltrate on histopathological examination. In more severe cases, yellow dots are found (Figure 4). Dermoscopy has a specificity of $98 \% .9^{9}$ There are major and minor criteria for hair dermoscopy. The diagnosis of FPHL is made if it meets 2 major criteria or 1 major criteria and 2 minor criterias. In the major criteria found (1) more than 4 yellow dots in the frontal region, (2) differences in hair thickness in the frontal area: occipital less than normal, (3) in the frontal region $>10 \%$ thin hair $(<0.03 \mathrm{~mm})$. Minor criteria found (1) an increase in the ratio of single pilosebaceous units in the frontal: occipital region, (2) velus hair, (3) perifollicular discoloration..$^{9,12}$

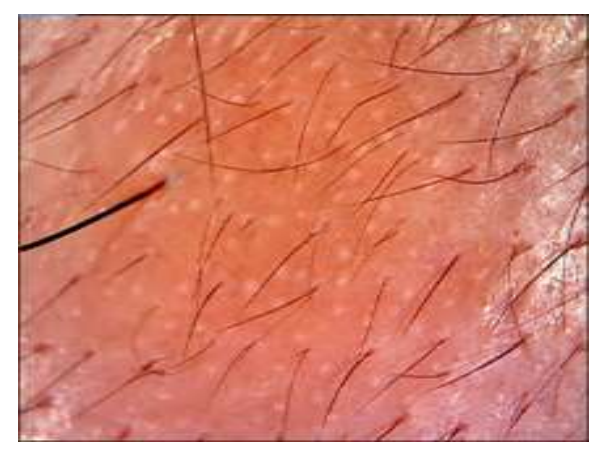

Figure 4. Yellow dots in dermoscopy of FPHL patient.

If hair loss occurs diffusely and does not on specific location, additional laboratory tests were required, thyroid stimulating hormone (TSH) and serum iron levels in patients with a history of iron deficiency, in diet, or a history of bleeding. ${ }^{6,13}$ Laboratory testing for androgens do not become routine. Serum androgen examination should be considered, especially in women with irregular menstruation, hirsutism, moderate-to-severe adult acne, and/or galactorrhea. ${ }^{14}$ At least, free/total testosterone with or without dehydroepiandrosterone sulfate (DHEA-S) examination should carried out in that case. ${ }^{2}$ 
ISSN 25980580

Histopathological examination were needed when the diagnosis of FPHL is uncertain. Two biopsy punch $4 \mathrm{~mm}$ size from the middle area of hair baldness are taken following the hair shaft from lateral to midline to the subcutaneous fat tissue where the anagen hair bulb is located. Biopsy is not done in the temporal area because the hair follicles that shrink can be found in that area even though there is no FPHL. Vertical and horizontal biopsy pieces are parallel to the surface of the skin. Horizontal cuts can quickly assess the number of hair follicles, diameter, and morphology. ${ }^{10}$ Characteristics of the histopathological results are an increase in the number of miniaturization of hair follicles and progressive changes in terminal hair to velus hair. In FPHL, the ratio of terminal hair to velus hair is $>3: 1$, whereas in normal hair the ratio is $>7: 1$. Other histopathological features of FPHL show a reduction in hair follicle size, depth, and diameter of the hair shaft, with an increase in telogen: anagen ratio. ${ }^{10,13}$ Terminal hair has a diameter of more than $0.06 \mathrm{~mm}$, whereas velus hair has a diameter of $0.03 \mathrm{~mm}$ or less and thinner. ${ }^{14}$

\section{Diagnosis}

The diagnosis of FPHL is made on the basis of the patient clinical condition (Figure 5). ${ }^{1}$ Generally, FPHL is clinical diagnosis, ${ }^{2}$ there is no need for additional examination to establish a diagnosis of hair loss with a typical pattern.

In anamnesis, some things that need to be asked to patients with suspected FPHL are the onset of age, duration, and progression of hair loss. Area of hair thinning usually occurs in the frontal, parietal, vertex, but can occur diffuse thinning. Family history of baldness is often be positive. Other things that need to be exclude as a cause of hair loss are medical conditions within 1 year before hair loss and history of other drugs/medication, such as iron deficiency, infections, thyroid disorders, strict diet, chemotherapy drugs, proandrogen hormones, antithyroid. ${ }^{1,2}$ To get rid of presence of signs of hormonal dysregulation in polycystic ovarian syndrome (PCOS), fertility, amenorrhoea, irregular menstrual cycles, abortion, hyperandrogen signs (excessive hair growth, acne) need to be examined. ${ }^{10,12}$

On physical examination, scalp and hair are examined, as well as whole body hair on women with hair loss complaints. Examination of the whole body's hair to identify the signs of hyperandrogenism, such as, excessive terminal hair in the body, acne, seborrheic, and 
obesity. ${ }^{9,10}$ In FPHL, normal scalp is found, no cicatric, terminal hair loss, variations in hair size, and miniaturization of hair. ${ }^{12}$

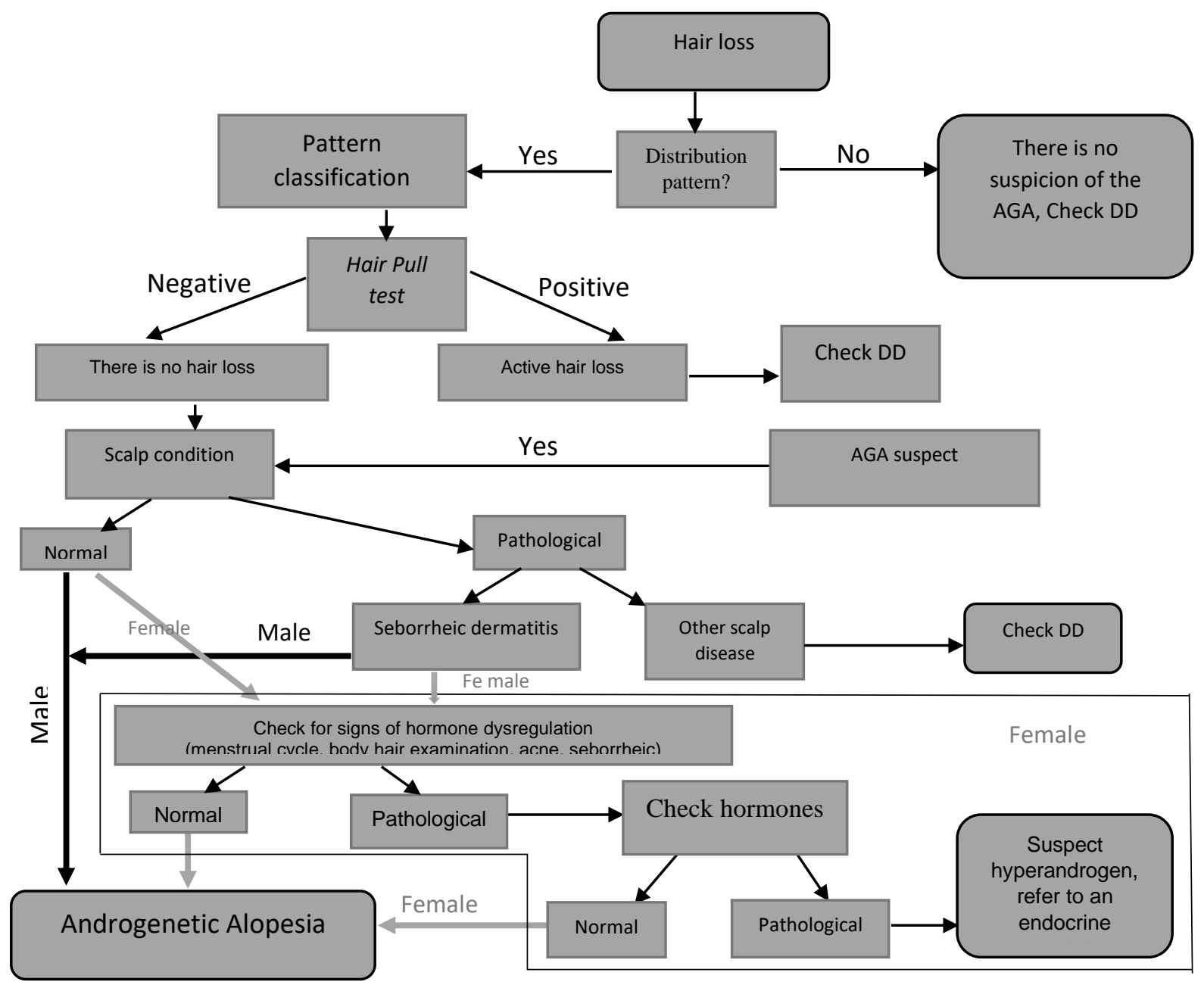

Figure 5. Diagnosis algorithm of hair loss pattern. ${ }^{11}$

The hair expert consensus proposed an assessment to diagnose and quantify female pattern hair loss using The 'Female Pattern Hair Loss Severity Index (FPHL-SI) to assess the severity scale with a value of 0-20 (Table 1). The severity index of FPHL is assessed through hair loss (visual shedding scale (Figure 6) and hair pull test), center hair density (Sinclair scale), and trichoscopy. A value of 0-4 indicates not a diagnosis of FPHL, 5-9 indicates an early stage of FPHL, and a higher value indicates an advanced severity. ${ }^{15}$ 
ISSN 25980580

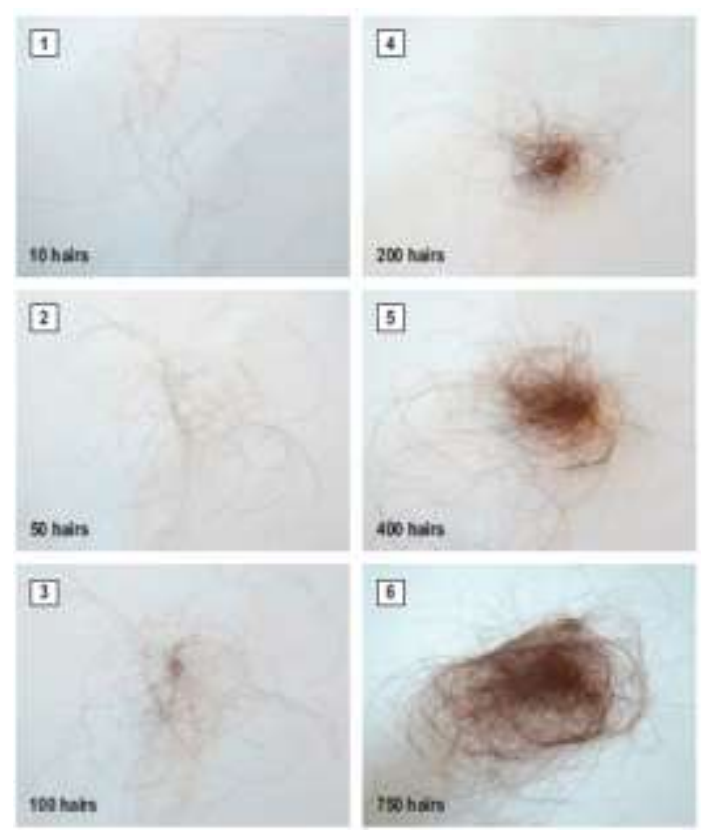

Figure 6. Visual shedding scale. ${ }^{6}$

Table 1. FPHL-SI assessment sheet (maximum score of 20) ${ }^{15}$

\begin{tabular}{|c|c|c|c|c|c|c|c|c|c|}
\hline \multirow{2}{*}{$\begin{array}{l}\text { FPHL-SI } \\
\text { diagnostic } \\
\text { criteria }\end{array}$} & \multicolumn{9}{|c|}{ FPHL-SI score } \\
\hline & 0 & 1 & 2 & 3 & 4 & 5 & 6 & 8 & 10 \\
\hline $\begin{array}{l}\text { Increased hair } \\
\text { loss: } \\
\text { Shedding scale/ } \\
\text { hair pull test }\end{array}$ & $\begin{array}{l}\text { The Sinclair } \\
\text { Scale 1- } \\
4 / \text { negative } \\
\text { pull test } \\
0\end{array}$ & & $\begin{array}{l}\text { The Sinclair } \\
\text { scale 5/6 / } \\
\text { positive pull } \\
\text { test } \\
2\end{array}$ & & & & & & \\
\hline $\begin{array}{l}\text { Midline Hair } \\
\text { Density: } \\
\text { Sinclair hair } \\
\text { density scale }\end{array}$ & $\begin{array}{l}\text { Sinclair 1 (NH } \\
\text { I-II) } \\
0\end{array}$ & & & & $\begin{array}{l}\text { Sinclair } \\
2 \\
\text { (NH III) } \\
4\end{array}$ & $\begin{array}{l}\text { Sinclair } \\
3 \\
\text { (NH IV) } \\
6\end{array}$ & $\begin{array}{l}\text { Sinclair } \\
4 \\
(\mathrm{NH} \mathrm{IV}) \\
6\end{array}$ & $\begin{array}{l}\text { Sinclair } \\
5 \\
(\mathrm{NH} \mathrm{V}) \\
8\end{array}$ & $\begin{array}{l}\text { Sinclair } \\
6 \\
\text { (NH VI- } \\
\text { VII) } \\
10\end{array}$ \\
\hline $\begin{array}{l}\text { Trichoscopy: } \\
\text { (A) Difference in } \\
\text { hair diameter }\end{array}$ & $\begin{array}{l}<20 \% \text { hair } \\
0\end{array}$ & & & & & $\begin{array}{l}>20 \% \\
\text { hair } \\
5\end{array}$ & & & \\
\hline $\begin{array}{l}\text { Trichoscopy: } \\
\text { (B) Three / one } \\
\text { hair per } \\
\text { follicular unit } \\
\text { (FU) There is } \\
\text { no difference } \\
\text { between the } \\
\text { frontal and } \\
\text { occipital } \\
\text { areas }\end{array}$ & $\begin{array}{l}\text { Tidak ada } \\
\text { perbedaaan } \\
\text { antara area } \\
\text { frontal dan } \\
\text { oksipital } \\
0\end{array}$ & $\begin{array}{l}\geq 25 \% \text { one } \\
\text { hair / FU or } \\
\geq 25 \% \\
\text { reduction in } \\
\text { three hairs / } \\
\text { FU between } \\
\text { frontal and } \\
\text { occipital } \\
1\end{array}$ & $\begin{array}{l}\geq 50 \% \text { one } \\
\text { FU hair } \\
2\end{array}$ & $\begin{array}{l}\geq 75 \% \\
\text { one FU } \\
\text { hair } \\
3\end{array}$ & & & & & \\
\hline \multicolumn{10}{|l|}{$\begin{array}{l}\text { Total FPHL-SI } \\
\text { score }(0-20) \text {. } \\
\text { 0-4 is not FPHL } \\
\text { 5-9 initial FPHL } \\
\geq 10 \text { FPHL }\end{array}$} \\
\hline
\end{tabular}


ISSN 25980580

\section{Management}

The goal of FPHL management is to stop progressive hair loss and stimulate hair growth. ${ }^{1}$ Early management and combination terapi would give good result. To date, FDAapproved FPHL therapies include $2 \%$ minoxidil topically, surgical therapy, and low-level laser therapy (LLLT). ${ }^{2}$ Other alternative therapies that may be effective, but require further research, such as hormonal therapy, microneedling, and PRP. ${ }^{16}$ The FPHL therapy algorithm is adjusted to the severity according to Ludwig's criteria. ${ }^{2}$ In general, FPHL therapy is classified into pharmacological (topical and systemic) therapy, hair transplantation and laser, aesthetic (wig, hair extension, camouflage), and alternative therapies that need further investigations. ${ }^{1,2,16}$ (Figure 7)

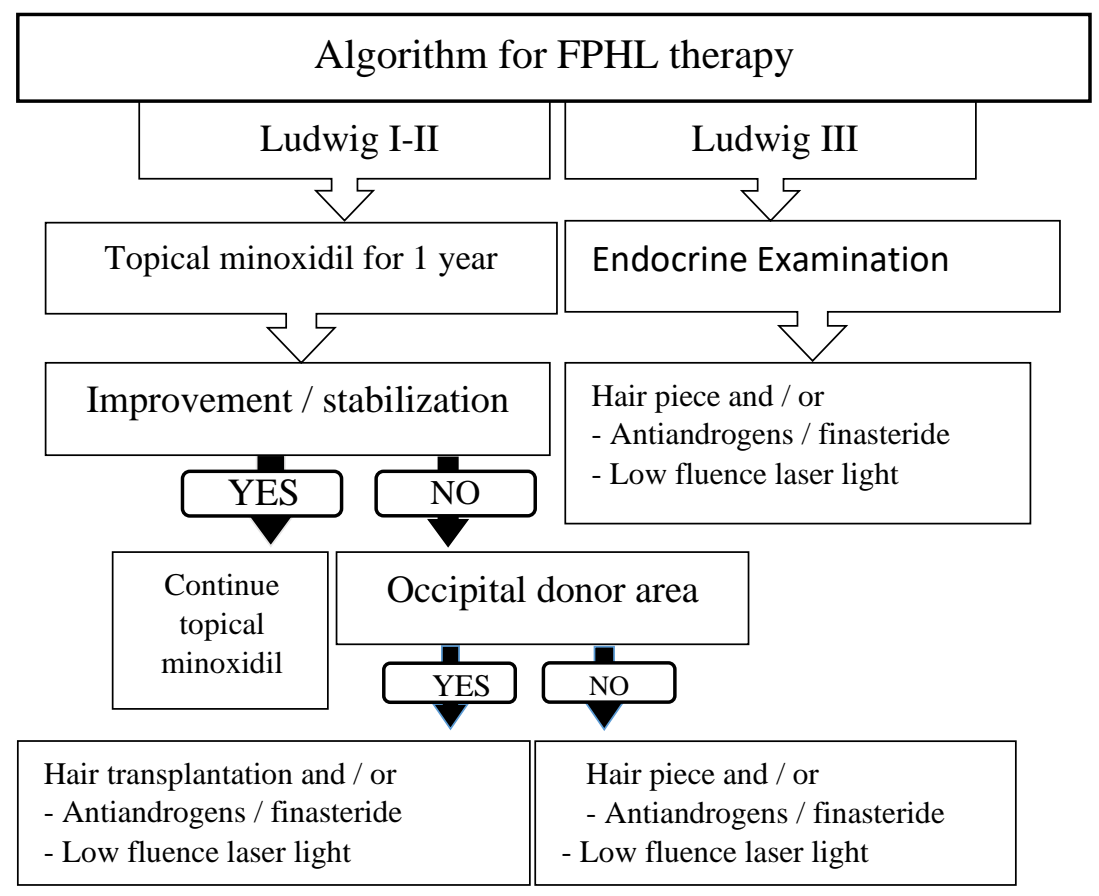

Figure 7. FPHL management algorithm ${ }^{2}$ 
ISSN 25980580

\section{Pharmacological Therapy}

\section{$\underline{\text { Topical minoxidil }}$}

Minoxidil is an antihypertensive derivative of piperidinopyrimidine which orally causes vasodilation and hypertrichosis. In topical use, minoxidil increases terminal hair density. Minoxidil does not have anti-androgen effects but increases follicular proliferation directly, produces anagen hair, and increases the size of hair follicles. ${ }^{1,2}$

Minoxidil exerts an effect when converted to a form of active metabolite, minoxidil sulfate, by the enzyme sulfotransferase in the outer hair roots of anagen follicles. The exact mechanism of minoxidil can accelerate hair growth is still unclear. Minoxidil sulfate opens the ATP-potassium pathway in the cell membrane, thus giving a vasodilating effect, but this vasodilating effect has no effect on hair growth. Minoxidil effects that might affect hair growth include: ${ }^{16}$

1. Increased expression of vascular endothelial growth factor (VEGF) mRNA in papilla dermis causing angiogenesis in papilla dermis.

2. Activation of cytoprotective prostaglandin synthase-1, a cytoprotective enzyme that stimulates hair growth.

3. Increased expression of hepatocyte growth factor (HGF) mRNA which is a hair growth promoter

Topical minoxidil is available in $2 \%$ and $5 \%$ solutions and $5 \%$ foam. Minoxidil used for FPHL therapy is $2 \%$ solution. Topical minoxidil solutions are given to the scalp in dry conditions twice daily for $1 \mathrm{ml}$ each application for at least 6 months. Minoxidil solution or foam is maintained at least 4 hours before the next shampoo. This therapy is a long-term therapy and takes 4-6 months before the drug starts working and the maximum effect is expected to occur after 1 year. Patients need to be informed that in the first 8 weeks of use of topical minoxidil, hair loss can still happen. ${ }^{2,12,16}$

Minoxidil contains propylenglycol which can give side effects such as local irritation, hypertrichosis, and contact dermatitis. This can be reduced by the use of a $2 \%$ concentration solution and the type of foam that contains less of that material. ${ }^{2,6}$ The effectiveness of minoxidil in FPHL shows a level of evidence $1^{1.16}$ 


\section{Hormonal therapy}

The process of androgen conversion and binding with androgen receptors are targeted in hormonal therapy in FPHL. Included in FPHL hormonal therapy are 5- $\alpha$-reductase and anti-androgen inhibitors. ${ }^{16,17}$

\section{5-a-reductase inhibitors}

In the human body there are 2 types of 5 - $\alpha$-reductase inhibitors. Type $\mathrm{I}$ is dominant in the liver, skin, and scalp while type II is dominant in the prostate and genitourinary tract fractures, and hair follicles. ${ }^{6}$ Initially, 5 - $\alpha$-reductase inhibitors were used for the treatment of benign prostatic hyperplasia (BPH). Finasteride and dutasteride are 2 drugs that inhibit the action of the 5- $\alpha$-reductase enzyme. The 5- $\alpha$-reductase enzyme is the target of treatment in FPHL because it plays a role in the process of converting testosterone to a stronger form of androgen, DHT which has the ability to bind to androgen receptors 5 times greater than testosterone. . $^{2,16}$

Finasteride, a synthetic steroid-azo, is very potent and sensitive to type 2 - $\alpha$-reductase inhibitors. It binds to 5- $\alpha$-reductase isoenzymes and prevents the conversion of testosterone to DHT. ${ }^{2,6}$ Finasteride $1 \mathrm{mg}$ daily can reduce DHT concentration in scalp by $64 \%$, and in serum as much as $68 \% .^{7}$ Finasteride has not been accepted for the treatment of FPHL and its effectiveness in FPHL is still controversial. In postmenopausal FPHL women, the use of finasteride $1 \mathrm{mg}$ daily did not show a significant effectiveness of anagen: telogen and terminal hair: velus ratio (level of evidence 2). ${ }^{16}$ Further research is needed for higher doses in a group of female patients with FPHL. The use of finasteride in FPHL patients of childbearing-age requires a safe method of contraception because it has been shown to cause feminization in male fetuses. Another side effect is an increase in the hormone estrogen due to the effects of aromatase which converts testosterone to estradiol so that this therapy is not given to patients with a history of breast cancer in the patient or family. ${ }^{16,17}$

Finasteride is quickly absorbed and reaches peak levels in plasma after 1-2 hours of consumption. The half-life of finasteride plasma is 6 hours. As many as $90 \%$ of the drug binds to plasma protein. Finasteride is metabolized in the liver by hydroxylation and oxidation of P450 via the $3 \mathrm{~A} 4$ pathway without interaction with other drugs that are metabolized by cytochrome P-450 such as warfarin, theophylline, digoxin, and propranolol. ${ }^{16}$ 
Dutasteride is a type I and II-5-reductase inhibitor. When compared with finasteride, dutasteride has three times more potent in inhibiting type I 5- $\alpha$-reductase and 100x more potent in inhibiting type 5 - $\alpha$-reductase. It has teratogenic effects and increase the risk of breast cancer. In male AGA, dutasteride is given at a dose of $0.5 \mathrm{mg}$ daily, but FDA does not recommend for FPHL. ${ }^{16,17}$

\section{Anti androgen}

Oral anti androgens for FPHL still need further investigations. There is no strong enough evidence to support the use of oral anti androgens to increase or prevent the progression of FPHL. Oral anti androgens that are currently being studied and used as alternative therapies on FPHL are spironolactone, cyproterone acetate, and flutamide (level of evidence 3$)^{16}$

Spironolactone is off-labeled for FPHL therapy at a dose of 100-200 mg daily for a minimum of 6 months. $^{2}$ Spironolactone is a potassium-saving diuretic drug, aldosterone antagonist. ${ }^{1}$ Spironolactone acts as an anti-androgen by reducing the amount of testosterone and inhibiting androgen receptors in target tissue. This drug is commonly used to treat hirsutism related to PCOS. The use of spironolactone in women of childbearing-age requires contraception to reduce menorrhagia. Spironolactone side effects are postural hypotension, menorrhagia, lethargy, nausea, feminization in male fetuses, and hyperkalemia. Spironolactone is contraindicated in patients with renal insufficiency, hyperkalemia, pregnancy, abnormal uterine bleeding, woman with predisposition to breast cancer. ${ }^{16,17}$

Cyproterone acetate is given at a dose of $50 \mathrm{mg}$ daily on days 1-10 of the menstrual cycle and 35 micrograms of ethinyl estradiol on days 1-21 of the menstrual cycle or $100 \mathrm{mg}$ of cyproterone acetate on days 5-15 of the menstrual cycle and 50 micrograms of ethinyl estradiol on days 5- 25 menstrual cycles. ${ }^{2}$ This drug directly block androgen receptors and decrease the amount of testosterone by suppressing follicle stimulating hormone (FSH) and luteinizing hormone (LH). Side effects of these drugs include mood disorders, liver toxicity feminization in male fetuses, menstrual cycle disorders, weight gain, depression, decreased libido, and nausea. ${ }^{3,16}$

Flutamide is an anti androgen that inhibits androgen binding with androgen receptors. This drug is effective for the treatment of hirsutism and FPHL with hyperandrogens 
Flutamide is given at a dose of $62.5 \mathrm{mg} /$ day and promotes hair growth after 6 months of use and a long-term stable effect. The side effect of the drug is liver toxicity. ${ }^{3,16}$

\section{Non-pharmacological Therapy}

\section{Low level laser therapy}

The LLLT device was first cleared for use in management of baldness and approved by the FDA in 2007. ${ }^{18,19}$ Until the end of 2014, the LLLT that was cleared for management of hair loss is HairMax LaserComb® (Lexington Internastional, Boca Raton, FL), He-Ne laser, MEP 90 stationary hood (Hartland Technologies), Theradome laser helmet (Theradome, Los Angeles, CA), and Apira iGrow laser helmet (Apira Science Inc., Boca Raton, FL). The HairMax LaserComb and Apira iGrow laser helmet are the only devices with published clinical findings in peer-reviewed journals. ${ }^{19}$

The LLLT, a 650-900 nm infrared, can cause proliferation, migration, oxygenation, and adhesion as well as the transition from telogen to anagen. Cytochrome $\mathrm{C}$ oxidase (COO) absorbs infrared light resulting in the release of nitric oxide (NO) which binds $\mathrm{O} 2$, causing electron transport to produce ATP and reactive oxygen species (ROS) through respiration in the mitochondria. Another hypothesis states that LLLT activates COO as nitrate reductase, causing the release of NO from the intracellum resulting in vasodilation and accumulation of ROS and ATP resulting in cell proliferation, migration, oxygenation, and adhesion. LLLT rays increase the signal wingless family (Wnt) and extracellular receptor kinase (ERK) thereby increasing transcription factors including Lef1. Transcription factors produce gene expression and release of paracarin stimulation. Paracrine signals along with infrared light produce keratinocyte proliferation and transition to the anagen phase. ${ }^{17,19}$

The LLLT that are FDA approved have a wavelength of $655 \mathrm{~nm}$ with 3 types of light 7,9,12 beams. The optimal dose or therapeutic regimen for LLLT is unknown. Most LLLT devices are used 15-20 minutes, every day or 3 times / week for 26 weeks. Furthermore, maintenance therapy is continued 1 time / week for 6 months. ${ }^{18}$ The advantage of LLLT is no side effects and easy to use. Jimenez, et al (2014) showed that the use of HairMax LaserComb® at $128 \mathrm{MPHL}$ and $141 \mathrm{FPHL}$ can increase terminal hair density after 26 weeks of therapy. ${ }^{20}$ 
ISSN 25980580

\section{$\underline{\text { Hair Transplantation }}$}

Hair transplantation is the treatment of choice for severe FPHL and is not successful with pharmacological therapy (level of evidence 4). ${ }^{16}$ This is contraindicated in patients with uncontrolled systemic diseases, such as hypertension, heart disease, and diabetes mellitus. The presence of local diseases such as cutaneous lupus erythematosus, morphea, alopecia areata, and scalp folliculitis should be treated at least 6 months before a hair transplant. ${ }^{21}$ Before the transplantation, the medical conditions, history of medications, family history of alopecia, realistic expectations of patients for surgical therapy, and donor area conditions should be consider. $^{22}$

The gold standard for hair restoration surgical therapy is follicular unit transplant (FUT) ${ }^{21}$ Graft in FUT can be taken using strip harvest or folicullar unit extraction (FUE) technique. In the harvest strip technique, strips containing hair are excised from the donor region and cut under a microscope to FUT, the donor area is taken with a length of $18 \mathrm{~cm}$ and a width of $1 \mathrm{~cm}$ obtained 1800 follicular units (100 follicular $\mathrm{U} / \mathrm{cm} 2)$. In the FUE technique, FUT is extracted directly from the donor area by punch biopsy with a diameter of 0.8-1.2 mm so that it does not require stitches. The donor area taken is the occipital area. ${ }^{2,23}$

\section{Camouflage}

Camouflage is an options for hair baldness management include partial or full wigs, hair extensions, concealing powder and sprays, and tatto. Camouflage is the simplest, easiest, and cheapest way to manage androgenetic alopecia. Camouflage therapy can be done by scalp coloring. Color selection is similar to hair color, thus giving the illusion of thicker hair. Powder that is applied on the scalp to hide baldness is water resistant and can be remove with shampoo. After application, then the hair is brushed to distribute the powder evenly. In addition to powder, camouflage material can also be lotion and spray. The limitation of this camouflage material that requires daily use and water activities can distort the camuflage. ${ }^{14,24}$

Some diffuse AGA patients prefer to use a wig. Wigs can be washed and styled and can cover baldness with natural-looking. Wigs can be made of real or synthetic hair. Wigs derived from real human hair can last 3-4 years, while synthetics wigs are replaced every 3-6 months. The real human hair wig looks more natural, can be adjusted with low heat, cooler 
when worn, can be colored, but it costs more, requires hair and care settings, is more prone to fading due to sunlight and the environment, heavier than a synthetic wig. While the synthetic wigs are easy maintenance, cheaper, lighter, less prone to fading due to sunlight. The synthetic wigs cannot be dyed, hotter when used, unnatural-looking, and more prone to heat damage $^{.24}$

Another hair camouflage material is hair extensions, usually made from animal hair such as horses and sheep. Hair extension is a strand of synthetic hair or hair that comes from humans and is attached to hair fibers using glue, braids, sewing or clips. Unfortunately, hair extensions can make alopecia worse due to traction. ${ }^{24}$

\section{$\underline{\text { Platelet Rich Plasma }}$}

Platelet rich plasma is an autologous platelet concentration containing a small amount of plasma which can accelerate the rejuvenation of skin and hair follicles due to growth factors and cellular adhesion molecules. This new modality in alopecia therapy activate the stem cells in the hair bulb area and induce the expression of hair growth factors related to genes to restore the anagen hair-forming mediator. The PRP contains 20 types of growth factors such as platelet derived growth factor (PDGF) which stimulates the growth of the dermis mesenchyme, vascular endothelial growth factor (VEGF) which increases the hair follicle vascularization, epidermal growth factor (EGF) which increases growth towards the anagen phase and prevents growth of the anagen phase follicular regression, insulin-like growth factor 1 (IGF-1) which slows apoptosis, fibroblast growth factor (FGF) which increases growth towards the anagen phase, nerve growth factor (NGF) which stimulates hair growth and slows apoptosis. Platelet concentrations in PRP preparations 3-5 times higher than concentrations in blood. ${ }^{5,25}$ Administration of PRP into the skin perform through mesotherapy injection or microneedling methods. ${ }^{5}$

Khatu, et al (2014) reported that 9 of 11 AGA patients treated with PRP showed negative hair pull test, increase hair volume and hair-covered areas of baldness after 4 sessions of PRP. ${ }^{26}$ Greco, et al reported that there is a significant increase in hair density and diameter of AGA patients in the PRP group. ${ }^{27}$ Singhal, et al showed that in 10 AGA patients treated with PRP for 3 months, the pull test results were reduced by $65 \%$. New hair growth was obtained in 6 patients in 10 days and 4 patients in 15 days. ${ }^{28}$ 


\section{ISSN 25980580}

Although PRP is a simple, inexpensive, and applicable method for management of baldness and has enough theory to support hair restoration, however, the clinical evidence is still weak. ${ }^{29,30}$ The PRP is a safe procedure, complications that usually occur after the procedure are pain at the injection site, headache, swelling, redness, infection, and allergic reactions such as urticaria. ${ }^{26}$

\section{Microneedling}

Microneedling is a minimally invasive procedure, using multiple fine needles that are inserted into the stratum corneum. Microneedling produces micropuncture so that it accelerates the process of wound healing, followed by the release of PDGF, activation of stem cells in the hair bulb area, and induction of hair growth factors associated with genes namely VEGF, $\beta$-catenin, Wnt3a, and Wnt10b, forming collagen and neovascularization. Microneedling facilitates penetration of other hair growth promoting therapies, such as minoxidil, PRP, topical steroid to stimulate the growth of hair follicle. ${ }^{31}$

Microneedling therapy can use a tubular roller surrounded by fine needles with a length between $0.5-2.5 \mathrm{~mm}$ which is rolled over the skin repeatedly in a vertical, horizontal, diagonal direction 15-20 times so as to produce 250 holes $/ \mathrm{cm}^{2}$. Another device, dermapen, is inserted vertically on the scalp with certain speed and depth of penetration. Before procedure, topical anesthesia, a mixture of lignocaine and/or prilocaine/tetracaine needs to be applied and aseptic procedure is required. The final result of microneedling technique is erythema or bleeding spots. This technique is more effective if combined with PRP or minoxidil therapy 24 hours after the procedure. ${ }^{31}$ Dhurat, et al. compare microneedling and 5\% minoxidil twice daily versus $5 \%$ minoxidil alone in a pilot study, showed that mean change in hair count were statistically better in the microneedling plus minoxidil group after 12 weeks of treatment. ${ }^{32}$

\section{PROGNOSIS}

Early onset FPHL may lead to faster progression of hair loss. There is no therapy that can cure FPHL. ${ }^{13}$ This condition is progressive without therapy. However, the therapy provided can only slow the progression of hair loss by several years and stimulate partial hair growth. The response to therapy is generally slow and requires patience from patients and doctors. The cosmetic effects of FPHL also need to be considered so that in addition to 
pharmacological therapy, cosmetic camouflage can also be considered and hair transplant surgical treatment can be an option for severe case. ${ }^{17}$

This condiction has a social and psychological impact on patients. Treatment can only prevent the progression of hair loss and there is not cure of FPHL.

\section{References}

1. Olsen EA. Female Pattern Hair Loss. In: Peytavi UB, Tosti A, Whiting DA, Trueb RM, editors. Hair Growth and Disorders. $2^{\text {nd }}$ ed. Berlin: Springer, 2008.p. 171-83.

2. Shapiro J. Androgenetic alopecia: Pathogenesis, clinical features and practical medical treatment. In: Dunitz M. Hair Loss: Principles of Diagnosis and Management of Alopecia. $1^{\text {st }}$ ed. London: The Livery House. p.83-119.

3. Mesinkovska NA, Bergfeld WF. Hair: What's new in diagnosis and management? Female pattern hair loss update: diagnosis and treatment. Dermatol Clin;2013:119-27.

4. Shapiro J. Androgenetic alopecia: Pathogenesis, clinical features and practical medical treatment. In: Dunitz M. Hair Loss: Principles of Diagnosis and Management of Alopecia. $1^{\text {st }}$ ed. London: The Livery House. p.83-119.

5. Farid CI, Abdelmaksoud RA. Platelet-rich plasma microneedling versus 5\% topical minoxidil in the treatment of patterned hair loss. J Egypt Women Dermatol Soc. 2016;13:29-36.

6. Perling LC, Sinclair RD, Caelen LE. Alopecia. In: Bolognia JL, Schaffer JV, Cerroni L, editors. Dermatology. $4^{\text {th }}$ ed. New York: Elsevier, 2018. p. 1162-8.

7. Brough KR, Torgerson RR. Hormonal therapy in female pattern hair loss. Int J Womens Dermatol. 2017;3:53-57.

8. Paik JH, Yoon JB, Sim WY, Kim BS, Kim NI. The prevalence and type of androgenetic alopecia in Korean men and woman. Br J Dermatol. 2001;145:184-9.

9. Ramos PM, Miot HA. Female pattern hair loss: a clinical and pathophysiological review. An Bras Dermatol. 2015;90(4):529-43.

10. Vujovic A, Marmol VD. The female pattern hair loss: review of etiopathogenesis and diagnosis. Biomed Res Int. 2014;1-8. 
11. Peytavi UB, Blumeyer A, Tosti A, Finner A, Marmol V, Trakatelli M, et al. S1 guideline for diagnostic evaluation in androgenetic alopecia in men, women and adolescents. $\mathrm{Br} \mathbf{J}$ Dermatol. 2011;164:5-15

12. Herskovitz I, Tosti A. Female pattern hair loss. Int J Endocrinol Metab. 2013;11(4):e9860.

13. British Association of Dermatologists. Female pattern hair loss (androgenetic alopecia). [internet]. 2016. [cited 2018 June 25]. Available from: http://www.bad.org.uk/shared/get-file.ashx?id=3830\&itemtype=document

14. Legiawati L. Alopesia Androgenetik. MDVI.2013;40/2:96-101.

15. Harries M, Tosti A, Bergfeld W, Peytavi UB, Shapiro J, Lutz G, et al. Towards a consensus on how to diagnose and quantify female pattern hair loss-The 'Female Pattern Hair Loss Severity Index (FPHL-SI). J Eur Acad Dermatol Venereol. 2016;30:667-76.

16. Blumeyer A, Tosti A, Messenger A, Reygagne P, Marmol VD, Spuls PI, et al. Evidencebased (S3) guideline for the treatment of andogenetic alopecia in women and in men. $\mathrm{J}$ Dtsch Dermatol Ges. 2011;6:S1-57.

17. Dinh QQ, Sinclair R. Female pattern hair loss: current treatment concepts. Clin Interv Aging. 2007;2(2):189-99.

18. Ghanaat M. Types of hair loss and treatment options, including the novel low-level light therapy and its proposed mechanism. Southern Med J. 2010;103:917-21.

19. Gupta AK, Folley KA. A critical assessment of the evidence for low level laser therapy in the treatment of hair loss. Dermatol Surg. 2017;43(2):188-97.

20. Jimenez JJ, Wikramanayake TC, Bergfeld W, Hordinsky M, Hickman JG, Hamblin MR, et al. Efficacy and safety of a low-level laser device in the treatment of male and female pattern hair loss: a multicenter, randomized, sham device-controlled, double-blind study. Am J Clin Dermatol. 2014;1:1-13.

21. Sinclair RD. Androgenetic Alopecia and Pattern Hair Loss. In: Griffiths C, Berker J, Bleiher T, Chalmes R, Creamer D, editors. Rook's Textbook of Dermatology. $9^{\text {th }}$ ed. London: Wiley, 2016. p. 89.14-24.

22. Lee WS, Lee HJ, Choi GS, Cheong WK, Chow SK, Gabriel MT, et al. Guidelines for management of androgenetic alopecia based on BASP classification-the Asian consensus committee guideline. J Eur Acad Dermatol Venereol. 2013;27:1026-34. 
23. Rousso DE, Kim SW. A review of medical and surgical treatment options for androgenetic alopecia. JAMA Facial Plast Surg. 2014;16(6):444-50.

24. Saed S, Ibrahim O, Bergfeld WF. Hair camouflage: a comprehensive review. Int J Womens Dermatol. 2017;3:S75-80.

25. Schiavone G, Raskovic D, Greco J, Abeni D. Platelet-rich plasma for androgenetic alopecia: a pilot study. Dermatol Surg. 2014;40:1010-9.

26. Khatu SS, More YE, Gokhale NR, Chavhan DC, Bendsure N. Platelet-rich plasma in androgenetic alopecia: myth or an effective tool. J Cutan Aesthet Surg. 2014;7:107-10.

27. Greco J, Brandt R. The effects of autologous platelet rich plasma and various growth factors on non-transplanted miniaturized hair. Hair Transplant Forum Int 2009;19:49-50.

28. Singhal P, Agarwal S, Dhot PS, et al. Efficacy of platelet-rich plasma in treatment of androgenic alopecia. Asian J Transfus Sci 2015;9:159-62.

29. Adil A, Goldwin M. The effectiveness of treatments for androgenetic alopecia: a systematic review and meta-analysis. J Am Acad Dermatol. 2017;77:136-41.

30. Tawfik AA, Osman MA. The effect of autologous activated platelet-rich plasma injection on female pattern hair loss: a randomized placebo-controlled study. J Cosmet Dermatol. 2017;1-7.

31. Fertig RM, Gamret AC, Cervantes J, Tosti A. Microneedling for the treatment of hair loss? J Eur Acad Dermatol Venereol. 2018;32:564-9.

32. Dhurat R, Sukesh M, Avhad G, Dandale A, Pal A, Pund P. A randomized evaluator blinded study of effect of microneedling in androgenetic alopecia: a pilot study. Int $\mathbf{J}$ Trichology. 2013;5:6-11 